\title{
Vertebral artery occlusion by a cervical 'hour-glass' neurofibroma
}

\author{
JAMES D. GEISSINGER, GEORGE GRUNER, AND DANIEL RUGE \\ From the Department of Surgery, Veterans Administration Research Hospital, and \\ Northwestern University Medical School, Chicago, Illinois, U.S.A.
}

SUMMARY A case of total vertebral artery occlusion by a cervical 'hour-glass' or 'dumb-bell' neurofibroma is reported. To the author's knowledge this is the first reported case in the English literature. A causal relationship between the arterial occlusion and the patient's symptoms has been postulated. The angiographic study of these patients is further emphasized to enhance safer and more effectual removal of these lesions.

Kriss and Schneider (1968) introduced the concept of vertebral angiography in the evaluation of cervical neurofibromata. They emphasized the paucity of information in the literature (Conley, Chusid, and Schechter, 1964; Berrett, 1965; Allen, 1967) concerning vertebral angiography for neurogenic tumours of the head and neck and the absence of angiographic information regarding cervical neurofibromata. Their paper cites three cases which illustrate the anterior and medial displacement of the artery by these lesions, and the value of this knowledge to the neurosurgeon in planning his operative approach.

Our recent investigation of a patient studied by means of vertebral angiography demonstrated total occlusion of one of the vertebral arteries by a cervical 'hour-glass' neurofibroma. Review of the English literature indicates no reports of total vertebral occlusion by a cervical neurofibroma.

\section{CASE REPORT}

A 51 year old Japanese male furniture store manager was admitted to the Veterans Administration Research Hospital on 10 August 1970 with a one year history of neck and shoulder pain, accompanied by intermittent tingling sensations in the hands and feet occurring after rising from the prone position. He was aware of one episode of blurred vision followed by a momentary loss of consciousness when he turned his head sharply to the left upon entering his car onto an express-way from an access lane.

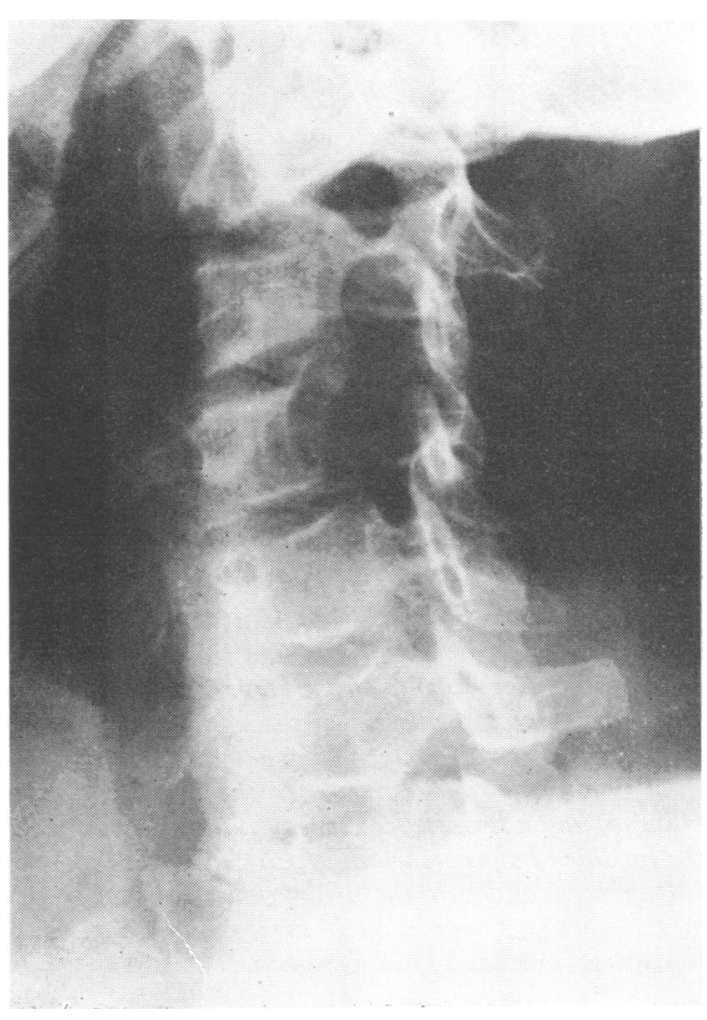

FIG. 1 A left lateral oblique view of the cervical spine which shows the enlargement of the C3-C4 foramen and the erosion into the body of C4 vertebra. Also note the thinned pedicle of $C 3$ and the absence of the pedicle of $C 4$ vertebra. 
Past history disclosed that he had a right hemilaminectomy at L5-S1 intervertebral disc for an extruded nucleus pulposus, and excision of a cystic mixed tumour of the left parotid gland in 1966.

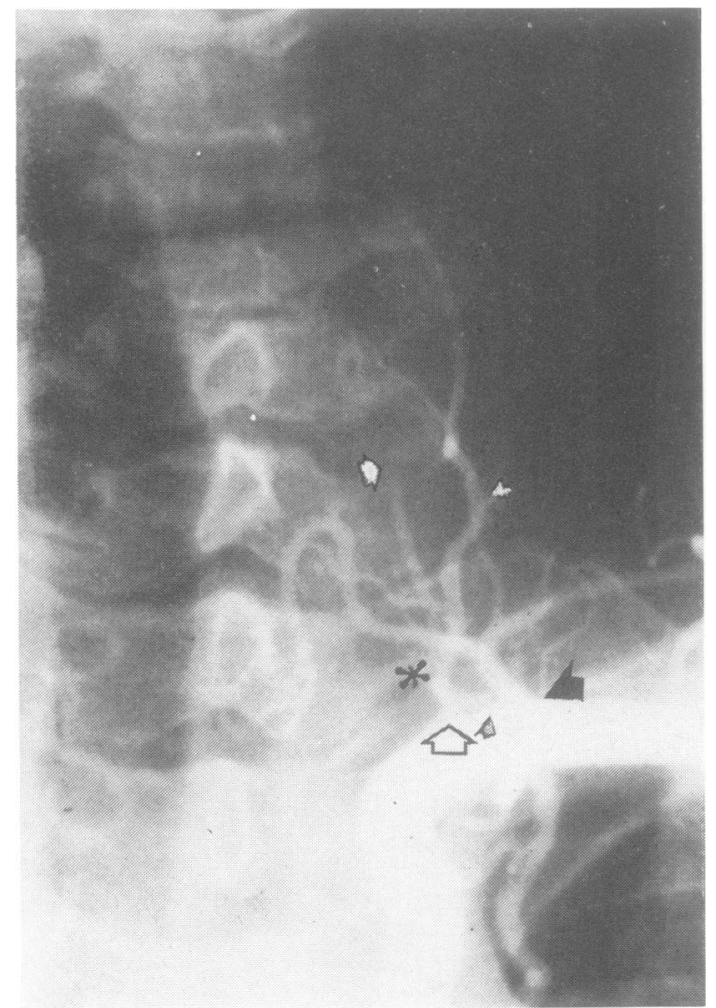

FIG. 2 Anterior projection during maximal arterial filling of a left retrograde brachial angiogram which demonstrates those arteries arising from the first portion of the left subclavian artery. The large white arrow designates the origin of the left vertebral artery which is the first branch of the subclavian artery. The small white arrow demonstrates the distal extent of filling of the left vertebral artery in its course toward the foramen transversarium of C6 vertebra. The small half-arrows designate the origin and course of the enlarged, tortuous deep cervical artery which crosses the transverse process of $C 7$ vertebra. The asterisk indicates the point of superimposition of the contrast shadows of the vertebral and the deep cervical arteries. The large black half-arrow points to the origin of the thyrocervical trunk which later divides into both the inferior thyroid artery coursing medially and anteriorly to the vertebral artery and the lateral coursing suprascapular artery. The internal mammary artery is seen to originate opposite the thyrocervical trunk.
Diabetes mellitus, diagnosed in 1968, has been treated with diet and oral hypoglycaemic agents.

EXAMINATION There was slight hypaesthesia over ơ the left thumb and first dorsal interosseous space.

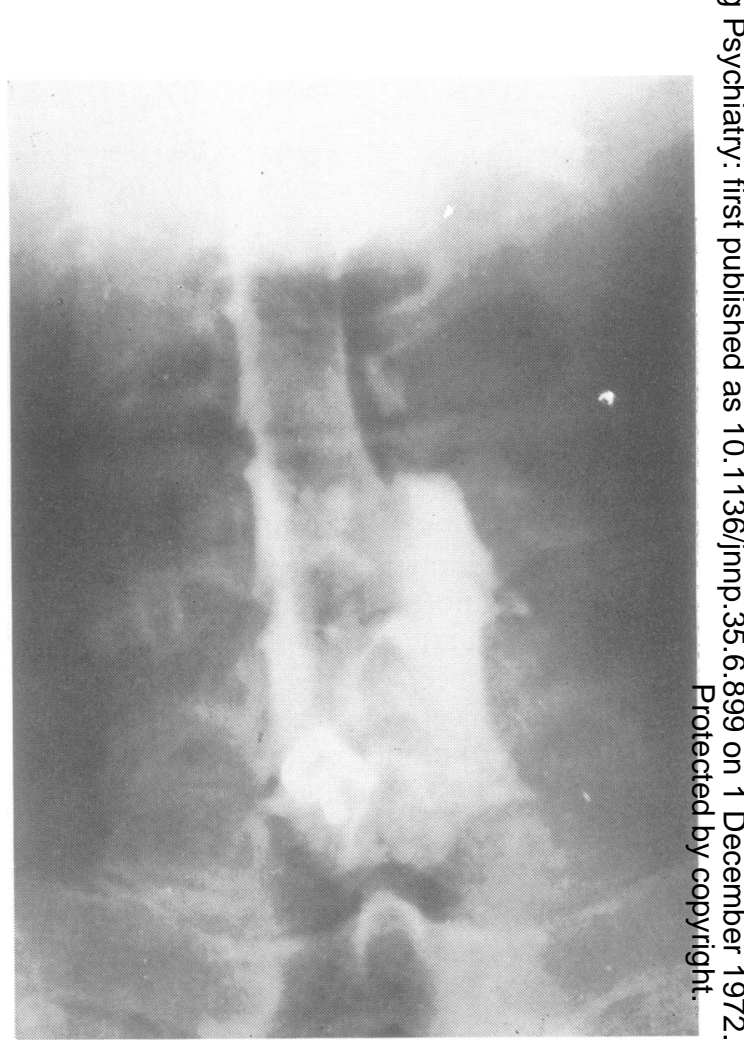

FIG. 3 A posteroanterior view of the cervical spine during iophendylate cervical myelography. The large extradural filling defect on the patient's left extends from $C 3$ to $C 5$ vertebrae and is pushing the cord shadow to the right side.

The abdominal reflexes were absent, but the remainder of the neurological examination was normal.

RADIOLOGICAL EXAMINATION Plain radiographs of the cervical spine (Fig. 1) revealed a smooth enlarge- $\frac{3}{6}$ ment of the intervertebral foramen on the left side 0 between vertebrae $\mathrm{C} 3$ and $\mathrm{C} 4$. The pedicle of $\mathrm{C} 3 ₹$ vertebra was markedly thinned, while the pedicle of $\frac{\text { ? }}{3}$ C4 vertebra was absent. There was also significant $>$ erosion into the posterior aspects of the bodies of $\mathrm{C} 3$ and $\mathrm{C} 4$ vertebrae.

A left retrograde brachial cerebral angiogram 
demonstrated the proximal portion and ascent of the left vertebral artery (Fig. 2). Although the course of the artery could be followed to C6 vertebra, there was cessation of flow distal to that point. Also noted during the study was a very large, tortuous deep cervical artery which was considered to be an enlarged collateral vessel in view of the obstructed vertebral artery.

A right retrograde brachial cerebral angiogram revealed a large right vertebral artery. At the junction of the right vertebral artery and the basilar artery, contrast material was seen to reflux proximally into the distal $3 \mathrm{~cm}$ of the left vertebral system lending supportive evidence of proximal left vertebral obstruction.

Cervical iophendylate (Pantopaque) myelography outlined a moderately large extradural filling defect on the left extending from $\mathrm{C} 3$ to $\mathrm{C} 5$ vertebra (Fig. 3).

OPERATION On 26 August 1970 a bilateral posterior cervical laminectomy was performed from C2 through C5 vertebrae. A firm, rubbery, yellowishwhite tumour was encountered on the left side and was found to have both intradural and extradural components. The intradural portion of the tumour was found to be an expansion of the fourth cervical root, while the extradural portion, with its waist at the C3-C4 foramen, was found to extend from the inferior aspect of $\mathrm{C} 2$ to the superior border of $\mathrm{C} 5$ vertebra, with ventral growth into the bodies of $\mathrm{C} 3$ and $\mathrm{C} 4$ vertebrae. After gutting the interior of the tumour, the entire encapsulated mass was removed. The third and fourth cervical nerve roots were incorporated into the neoplasm and had to be sacrificed. The histopathological diagnosis was neurofibroma.

POST-OPERATIVE COURSE The patient progressed well after surgery except for anaesthesia over the C3 and C4 dermatomes on the left and an occasional L'Hermitte's phenomenon. Because of only slight preservation of the pedicles of $\mathrm{C} 3$ and $\mathrm{C} 4$ vertebrae on the left, the patient was placed in a four-poster frame. Six months after laminectomy, cineradiography failed to reveal any subluxation or instability of the cervical spine. On 10 October 1970 the left parotid gland containing a $1 \times 2 \mathrm{~cm}$ oxyphilic adenoma was removed.

At present, the patient is working full time and no longer requires his brace. He complains of hypaesthesia and occasional pain in the left shoulder and continues to have episodes of momentary blurring of his vision plus dizziness if he turns his head to the left.

\section{DISCUSSION}

It is worthy of comment that our patient's complaint of an unexplained syncopal episode heralded by blurring of his vision, was probably related to his occluded left vertebral artery. Postoperatively he continues to experience 'blurred vision and dizziness' when he rotates his head to the left.

When Tatlow and Bammer (1957) injected the vertebral arteries of a cadaver, they showed that normally when the head is extended and the face turned to one side, there is compressive obstruction of the contralateral vertebral artery at the point where the artery passes through the transverse process of the atlas. This important anatomical fact is further stressed by Brain and Wilkinson (1967), who have clearly demonstrated it in cadaver material. Lest it might have ended in disaster no attempt was made to inject contrast material into our patient's right vertebral artery with his head rotated to the left. Although we lack angiographic confirmation of this phenomenon in our patient, it is quite probable that, without a compensatory flow through the already pathologically occluded left vertebral artery, he may sharply compromise his brainstem circulation by partially occluding the right vertebral artery in extreme rotation of his head to the left.

In planning any neurosurgical operation, the surgeon must rely heavily on all of the neuroradiological information which he can acquire to satisfy his ultimate goal. Ideally that goal is to achieve a total cure of the disease process without incurring any neurological deficit. In 1952, Love and Dodge reported their often quoted series of 'dumb-bell' neurofibromata of the cervical nerve roots, and mentioned a 5\% recurrence rate. Kriss and Schneider (1968) commented upon that low recurrence rate, but added that perhaps this figure could be improved upon in the future with the aid of preoperative vertebral angiography. The additional knowledge of arterial displacement not only aids the surgeon in a preoperative estimation of the tumour size, but also allows a more aggressive operative approach to effect a total cure. We would like to endorse the report of these surgeons.

In our patient it was valuable to know that the left vertebral artery had already been sacrificed 
by the neoplasm, and that we could attempt a total extirpation of the tumour without fear of troublesome haemorrhage or compromise of the brain-stem circulation.

\section{REFERENCES}

Allen, G. W. (1967). Angiography in otolaryngology. Laryngoscope, 77, 1909-1961.

Berrett, A. (1965). Value of angiography in the management of tumors of the head and neck. Radiology, 84, 1052-1058.

Brain, W. R., and Wilkinson, M. (1967). Cervical Spondylosis and Other Disorders of the Cervical Spine, p. 110. Heine mann: London.

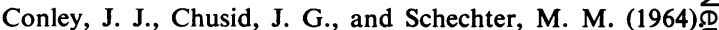
Angiography in head and neck surgery. Archives of Sur gery, 89, 609-618.

Kriss, F. C., and Schneider, R. C. (1968). The value of verte bral angiography in the treatment of cervical neurofibroma. Journal of Neurosurgery, 28, 29-34.

Love, J. G., and Dodge, H. W., Jr. (1952). Dumbbell (hour glass) neurofibromas affecting the spinal cord. Surgery? Gynecology and Obstetrics with International Abstracts obॉ Surgery, 94, 161-172.

Tatlow, W. F. T., and Bammer, H. G. (1957). Syndrome of vertebral artery compression. Neurology (Minneap.), $7 \overline{\bar{e}}$ 331-340. 